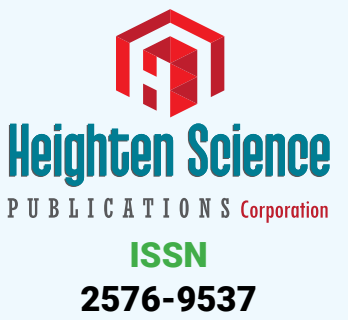

*Address for Correspondence: Mohamed Abdelhamid, Surgery Department, Faculty of Medicine, Beni Suef, Egypt, Tel: 00201062531899; Email:m.salah10.59@gmail.com;

mohamedsalah_2000@hotmail.com

Submitted: 01 January 2019

Approved: 21 January 2019

Published: 22 January 2019

Copyright: (c) 2019 Abdelhamid M, et al. This is an open access article distributed under the Creative Commons Attribution License, which permits unrestricted use, distribution, and reproduction in any medium, provided the original work is properly cited

Keywords: CBD exploration; Primary repair
Research Article

\section{Safety of primary common Bile Duct Closure}

\section{Mohamed Abdelhamid ${ }^{1 *}$, AM Bekeet ${ }^{1}$, MA Negida ${ }^{2}$, AZ Garib ${ }^{3}$ and SS Soliman ${ }^{4}$}

\author{
'Surgery Department, Faculty of Medicine, Beni Suef, Egypt \\ ${ }^{2}$ Surgery Department, Kasr El Aini Teaching Hospital, Faculty of Medicine, Egypt \\ ${ }^{3}$ Surgery Department, Faculty of Medicine, Egypt \\ ${ }^{4}$ Surgery Department, Faculty of Medicine, Fayoum, Egypt
}

\section{Abstract}

Primary closure of the common bile duct following exploration has been safely and effectively performed, as advocated by Halsted, provided no evidence of pancreatitis, cholangitis, or ampullary obstruction exists. This study was to gain back confidence to primary closure in selected cases. This study was conducted at Beniswaif University Hospital. Between July 2008 to May. 2014. Using this precedent, the operative management and post-operative course of 19 patients undergoing common bile duct (CBD) exploration for choledocholithiasis were studied, twelve had primary closure of the common bile duct following choledochotomy and exploration, and seven had T-tube placement.

Patients were selected for T-tube if there were pancreatitis, cholangitis, undue trauma, ampullary obstruction. Two patients in that study had bile leak, one in each group. Intravenous fluids were less in primary suture $(P<0.001)$. The long of stay were significantly less in primary suture $(P<0.001)$. The outcome of this study greatly support the safety of primary common bile duct closure in selected cases.

\section{Introduction}

Obstruction of the common bile duct as a result of the presence of stones has historically been corrected by opening the common bile duct and removing the stones [1]. In 1890, Ludwing Courvoisier was the first to perform a choledochotomy and remove a common bile duct stone [2]. As early as 1917, Halstead described primary closure of the common bile duct that was drained using a tube through the cystic duct stump [3]. There are surgeons who practice primary closure of the common bile duct after exploration and decry the use of post operation T-tube cholangiography [4].

The tube can be dislodged before a tract has developed and re-operation becomes necessary. There is a large amount of pain associated with the presence of the T-tube over such a long period. . Patients are reluctant to return to work with a T-tube in place and can lose from 3 to 4 weeks of work [1]. Even after the most meticulous precautions a proportion of patients will demonstrate residual stones on the post-operative T-tube cholangiogram [4]. In majority of surgical centers an external T-tube drainage was carried out in last century [5].

It is perfectly true that the common bile duct can be closed safely by primary suture with little risk of leakage [6Early dislodgment of the drain does not always require reoperation and post discharge films are not required. The patient has a smoother postoperative course, with less pain and an earlier return to work [1]. The contraindications to this procedure are undue trauma to the duct (for example removal 
of an impacted stone), suppurative cholangitis, associated pancreatitis, trans- duodenal procedures and when the common bile duct was of narrow caliber, thin walled where stenosis might follow primary suture [7]. Exploration of the common duct through the stump of the cystic duct does not give adequate access and is not recommended [4].

\section{Patients and Methods}

This study was conducted upon nineteen patients between July 2008 - May. 2014 at Beniswaif University Hospital with common bile duct stones, most of them had clinical jaundice, the others had abdominal pain and proved to be common bile duct stones by ultrasonography. There were 14 females and 5 males, age ranged from 24 years to 65 years with a mean age + SD of 52.2 years +10.3 . All were admitted and subjected to CBC, RBS, Liver function, kidney function and ultrasonography. Patient with comorbidity were excluded from the study.

\section{Methods}

1 - All patients got intra operative cholangiography through cystic duct cannulation, gallbladder or CBD.

2 - Anterior longitudinal choledochotomy between two stay sutures, $2 \mathrm{~cm}$ long terminated immediately above the duodenum. If this initial incision exposes calculi, they should be removed immediately.

3 - Proximal then distal duct exploration, with insertion of a small swab into the common hepatic duct to prevent stones passing up towards the liver during subsequent manipulation, to be removed after completion of exploration.

4 - The common bile duct was closed primarily using a 3-0 vicryl running stitch. It is imperative that only small bites of the common bile duct are taken. Then a post exploration cholangiogram was done through the cystic duct stump, then drain inserted.

5 - T-tube insertion was indicated if there were:

I Thin wall, narrow lumen.

II Undue trauma to the duct.

III Cholangitis, pancreatitis.

IV Transduodenal procedures.

A $2 \mathrm{~cm}$ long tube was placed in the choledochotomy incision and the duct closed around the tube with $2 / 0$ vicryl. A post exploratory T-tube cholangiogram was done, then drain inserted.

After approval of the ethical committee at our faculty, the procedure was well explained to the patients and a written consent is taken.

\section{Statistical analysis}

The data obtained were statistically analysed using chi-square test to compare the distribution of a categorical variable. A chi-squared test, also written as $\chi 2$ test, is any statistical hypothesis test where the sampling distribution of the test statistic is a chisquared distribution when the null hypothesis is true. Without other qualification, 'chisquared test' often is used as short for Pearson's chi-squared test. The chi-squared test is used to determine whether there is a significant difference between the expected frequencies and the observed frequencies in one or more categories T-test used to find the standard error of the difference between two means and testing the size of the difference by this standard error to find out the degree of probability. The t-test is any 
statistical hypothesis test in which the test statistic follows a Student's t-distribution under the null hypothesis.

A t-test is most commonly applied when the test statistic would follow a normal distribution if the value of a scaling term in the test statistic were known [8].

\section{Results}

The nineteen patients included in the study subjected to abdominal exploration due to common bile duct obstruction by a stone or stones as ERCP is not available. The choledochotomy repaired in 12 by primary suture, in 7 through placement of a T-tube, the indication for its placement were, three due to undue trauma during stones extraction, two due to narrow thin common bile duct and two having cholangitis with fever.

Two cases had bile leak through the drain that was inserted in the hepatorenal pouch, one in the primary closure (1/12) and one in the T-tube group (1/7). There were no manifestations of neither local nor general peritonitis. The bile leak in the patient with primary closure was minimal, started second post-operative day and stopped with conservative treatment on the fifth day while that with T-tube was moderate, started third post-operative day and stopped with conservative treatment on the ninth day. No patient was in need for re-operation (Table 1).

All patients were nothing per mouth NPO postoperative, the NPO period for primary suture ranged from one day to three days with a mean $+\mathrm{SD}$ ( standerd deviation) of 2 days +0.7 , while the NPO period for T-tube patients ranged from three days to seven days with a mean $+\mathrm{SD}$ of 4.8 day +1.2 , (Table 2 ). The volume of transfusion to patients with primary suture ranged from $2.5 \mathrm{~L} /$ day to $3.5 \mathrm{~L} /$ day with a mean $+\mathrm{SD}$ of $3.04+0.3$, the total amount of transfusion ranged from $2.5 \mathrm{~L} /$ admission to $9 \mathrm{~L} /$ admission with a mean $+\mathrm{SD}$ of $6.08 \mathrm{~L}+2.1 \mathrm{~L}$, while on the other hand the volume of transfusion in the T-tube patients ranged from $3 \mathrm{~L} /$ day to $4.5 \mathrm{~L}$ / day, the total amount of transfusion ranged from 13.5L / admission to 21 / / admission with a mean + SD of 15.2L + 5L (Table 3).

Regarding the long of stay it ranged in the primary suture from two days to five days with a mean $+\mathrm{SD}$ of 2.9 days +0.9 . It ranged in the $\mathrm{T}$-tube patients from eight days to fourteen days with a mean + SD of 10.2 days +2.2 (Table 4 ).

\section{Discussion}

The first common bile duct exploration was performed in 1884 using primary suture [7]. In 1890, Ludwing Courvoisier was the first to perform a choledochotomy and remove a common bile duct stone [2]. T-tube drainage was introduced on 1895,

\begin{tabular}{|c|c|c|c|}
\hline \multicolumn{2}{|c|}{ Table 1: Incidence of bile leak and reoperation. } & \multicolumn{2}{l|}{} \\
\hline PARAMETER & PS & T-TUBE & STATISTICS \\
\hline Bile leak & $1 / 12(8.3 \%)$ & $1 / 7(14.2 \%)$ & $\mathrm{x}^{2}=8.65 \quad \mathrm{P}<0.01$ \\
\hline Re-operation & - & - & - \\
\hline
\end{tabular}

Table 2: NPO duration.

\begin{tabular}{|c|c|c|c|}
\hline Table 2: NPO duration. & \multicolumn{1}{|c|}{ STATISTICS } \\
\hline PARAMETER & PS & T-TUBE & $\mathrm{t}=3.5 \quad \mathrm{P}<0.01$ \\
\hline NPO & 2 days \pm 0.7 & 4.8 days \pm 1.2 & $\mathrm{t}$
\end{tabular}

Table 3: Significance of fluid transfused.

\begin{tabular}{|c|c|c|c|}
\hline PARAMETER & PS & T-TUBE & STATISTICS \\
\hline Volume/day & $3.04 \mathrm{~L} \pm 0.3$ & $3.8 \mathrm{~L} \pm 0.5$ & $\mathrm{t}=3 \quad \mathrm{P}<0.01$ \\
\hline Volume/admission & $6.08 \mathrm{~L} \pm 2.1$ & $15.2 \mathrm{~L} \pm 5$ & $\mathrm{t}=5.7 \quad \mathrm{P}<0.001$ \\
\hline
\end{tabular}

Table 4: Significance of long of stay.

\begin{tabular}{|c|c|c|c|c|}
\hline PARAMETER & PS & T-TUBE & STATISTICS \\
\hline LOS & 2.9 days \pm 0.9 & 10.2 days \pm 2.2 & $t=10.3 \quad \mathrm{P}<0.001$ \\
\hline
\end{tabular}


and since that time primary suture had been abandoned. Mayo [9], Kiirschner [10], Mirrizzi [11], Edwards and Herriongton [12], Herrington et al. [13], have written articles supportive of primary common bile duct closure. Primary closure of the common bile duct following exploration has been safely and effectively performed, provided no evidence of pancreatitis, cholangitis or ampullary obstruction exists [14]. In majority of surgical centers an external T-tube drainage was carried out in last century, but is an external drainage the best method to be used? [5]. The current study aimed at sharing in returning confidence in primary suture procedure after common bile duct exploration and to establish criteria for including or excluding patients undergoing primary suture of bile duct closure. It is well known that the best treatment of common bile duct stones is ERCP whenever available and our study done on basis of ERCP absence.

Regarding the post-operative bile leak, it was $8.3 \%$ in the primary suture patients, while it was $14.2 \%$ in the T-tube patients $(\mathrm{P}<0.01)$, this in contrast to XU L et al. [6] who reported more bile leak in the primary suture patients more than that in T-tube patients. His bile leak incidence in primary suture patients was $4.1 \%$ while he reported an incidence of $2.9 \%$ in T-tube patients with no significant difference $(\mathrm{P}>0.05)$, generally XU L et al. had less incidence of bile leak than the current study with more leak in the primary suture patients than those with T-tube in reverse to current study where there was more leak in the T-tube patients. Sikic [7] reported like the current study less leak in the primary suture patients (1.6\%) than T-tube patients (7\%).

After operation the patients of primary suture started oral fluids after a mean period + SD of two days +0.7 of NPO, while the period for those of T tube was 4.8 days +1.2 with significant long NPO period $(\mathrm{P}<0.01)$, while it was 4.9 days and 7.3 days in the work of XU L et al. [6].

In the current study, the primary sutures patients had a mean volume of infusion per day + SD of 3.04 L / day+ 0.3, while that of T-tube was 3.8 L / day + 0.5. The mean volume of total amount of infusions in primary suture patients was $6.08 \mathrm{~L} /$ admission +2.1 , while it was $15.2 \mathrm{~L} /$ admission +5 for those with T-tube, this difference was significant $(\mathrm{P}<0.01)$ per day and highly significant $(\mathrm{P}<0.001)$ for the total amount of infusions per admission, these findings were also significant only $(\mathrm{P}<0.01)$ in the work of XU L et al. [6], who reported volumes of $9.1 \mathrm{~L}$ and12.8 L.

The mean long of stay was 2.9 days +0.9 in primary sutures patients, and 10.2 days +2.2 for patients with T-tube, this difference was highly significant (0.001), this was also reported by Payne and Woods [15] who found significant saving of hospital time after primary suture $(\mathrm{P}=0.05)$. The same also reported by Sikic et al. [7]. Williams et al. [16], who stated that the post-operative stay was significantly prolonged in the T-tube patients, to a median of 11 days, compared to 3 days in the primary sutures patients $(\mathrm{P}=0.001)$.

Regarding the most annoying complications of biliary surgery which is missed stones, in the current study no retained stones could be detected in both primary sutures patients and the T-tube patients, on the other hand it was $2.5 \%$ in primary closure and $8 \%$ in T-tube patients in the work done by Sikic [7]. Primary closure of common bile duct is a safe alternative of common bile duct restoration following exploration for lithiasis, with good results in long-term follow up [17], laparoscopic primary closure of CBD is safe and effective for the management of CBD stones, and can be performed routinely as an alternative to $\mathrm{T}$-tube drainage, the same was with us in our study through open surgery [18]. Primary closure after choledochotomy to clear stones from the CBD is a safe technique that confers excellent results and allows onestage treatment [19]. Closure of the common bile duct over T-tube after exploration is a widely practiced traditional method. However, its use may give rise to many complications. We do primary closure of common bile duct after exploration [20]. 
It is concluded that primary suture is a significantly less expensive procedure, spending less medication, I.V fluids, x-ray and laboratory tests, with a shorter postoperative stay when done on selected patients without pancreatitis, cholangitis nor ampullary undue trauma or pathology like stricture or stenosis, so primary suture is unjustified abandoned operative procedure that must be considered whenever the situations are suitable.

\section{References}

1. Seale AK, Ledet WP. Primary common bile duct closure. Arch Surg. 1999; 134: 22-24. Ref.: https://goo.gl/ZHHsNL

2. Hunter JC, Trust T. Laparoscopic cholecystectomy, intraoprative cholangiography and common bile duct exploration. In Nuhus LM, Baker RJ, Fischer JE (eds). Mastery of surg, $3^{\text {rd }}$ ed: Boston - little, Brown and company. 1997; 1098-1009.

3. Halstead WS. Surgical papers. Baltimore: Johns Hopkin University Press. 1924; 2: 427-472.

4. Ellis H. Choledocholithiasis. In Schwartz SI, Ellis H and Husser WC (eds). Maingot's abdominal operation, $8^{\text {th }}$ ed.: East Norwalk-Appleton-Century crotts. 1985; 1883-1808.

5. Piecuch J, Arendt J, Gradzik R, Rudzki M, Sosada K, et al. Primary suture following the bile duct exploration in cholelithiasis. Wrad Lek. 2004: 57: 241-244. Ref.: https://goo.gl/Y7wsk2

6. Xu L, Zheng Z, Chen K, Wu R, Mao G, et al. Primary common bile duct closure after choledochotomy Zhonghua Wai Ke Za Zhi. 2002; 40: 927-929. Ref.: https://goo.gl/z7SgCS

7. Sikic N, Tutek A, Strikic N. Primary suture vs. T-tube after common bile duct exploration. Przegl Lek. 2000; 57: 143-145. Ref.: https://goo.gl/zxswx3

8. Swinscow TDV, Campell MJ. Statistics at square one. BMJ Publishing group, Plymouth, Latiner Trend and company ltd. 1996; 1-138 $9^{\text {th }}$ ed. Ref.: https://goo.gl/wcbx79

9. Mayo WI. An address on the surgery of the hepatic and common bile ducts. Lancet. 1923; 1: 1299 1302. Ref.: https://goo.gl/qKioQd

10. Kirschner M. Operations on the gall bladder and the bile passage. In Kirschner M (ed). Abdomen and Rectum operative surgery. Philadelphia, Lippincott. 1933: 460-517.

11. Mirrizzi PL. Primary suture of the common bile duct in choledcholithiasis. Arch srug. 1942; 44: 44-54 Ref.: https://goo.gl/o469su

12. Edwards LW, Herrington JL. Closure of the common bile duct following its exploration. Am surg 1953; 137: 171-189-194. Ref.: https://goo.gl/SkL8j8

13. Dawson RE, Edwards WH, Edwards LW, Herrington JL. Further consideration in the evaluation of primary closure of the common bile duct following its exploration. Am surg. 1957; 145: 153-161. Ref.: https://goo.gl/iKgdmz

14. Sorensen VJ, Buck JR, Chungs K, et al. Primary common bile duct closure following exploration. Am surg, 1994; 60: 451-454. Ref.: https://goo.gl/TvBMaE

15. Payne RA, Woods WG. Primary suture or T-tube drainage after choledochotomy. Ann R coll Surg Engl. 1986; 68: 196-198. Ref.: https://goo.gl/QfSb26

16. Williams JA, Treacy PJ, Sidey P, Worthley CS, Townsend NC, et al. Primary duct closure versus T-tube drainage following exploration of the common bile duct. Aust NZJ Surg. 1994; 64: 823-826. Ref.: https://goo.gl/Q8wrXX

17. Rafailidis S, Ballas K, Symeonidis N, Pavlidis T, Psarras K, et al. Primary closure of common bile duct - Long-term results. The Internet Journal of Surgery. 2010; 23: 1528 -1531. Ref.: https://goo.gl/gJCHnz

18. Dong ZT, Wu GZ, Luo KL, Li JM. Primary closure after laparoscopic common bile duct exploration versus T-tube. J Surg Res 2014; 189: 249-254. Ref.: https://goo.gl/7eze6f

19. Estellés Vidagany $E$, Pozo DD, Tomás $P$, Ares $D$, et al. Eleven years of primary closure of common bile duct after choledochotomy for choledocholithiasis. Surg Endosc. 2016; 30: 1975-1982. Ref.: https://goo.gl/4LSsDr

20. Joshi MR, Singh DR. T-tube vs Primary Common Bile Duct Closure. J Nepal Med Assoc. 2010; 49: 199-203. Ref.: https://goo.gl/9RYS3o 